Research Institute for Quantitative Studies in Economics and Population Faculty of Social Sciences, McMaster University

Hamilton, Ontario, Canada

L8S 4M4

\author{
AGGREGATION EFFECTS ON PRICE AND \\ EXPENDITURE ELASTICITIES IN A \\ QUADRATIC ALMOST IDEAL DEMAND SYSTEM
}

Frank T. Denton and Dean C. Mountain

QSEP Research Report No. 374

July 2002

The authors are QSEP Research Associates. Frank Denton is a faculty member of the McMaster Department of Economics. Dean Mountain is a faculty member of the McMaster Michael G. DeGroote School of Business and an associate member of the Department of Economics.

The Research Institute for Quantitative Studies in Economics and Population (QSEP) is an interdisciplinary institute established at McMaster University to encourage and facilitate theoretical and empirical studies in economics, population, and related fields. For further information about QSEP and other reports in this series, see our web site 
April 2002

\begin{abstract}
$\underline{\text { ABSTRACT }}$
AGGREGATION EFFECTS ON PRICE AND EXPENDITURE ELASTICITIES

IN A QUADRATIC ALMOST IDEAL DEMAND SYSTEM

Frank T. Denton and Dean C. Mountain

McMaster University
\end{abstract}

While it is well known that demand elasticities calculated at the macro level will in general differ from those calculated at the micro level because of aggregation effects there remain the questions of how large the effects are, and how they vary with the degree of nonuniformity in the income distribution. We explore those questions with models based on a quadratic version of the Almost Ideal Demand System. We investigate the elasticity differences theoretically and then calibrate the models and generate numerical results, using income data for seven countries with widely different distributions. The aggregation effects are found generally to be rather small, even with highly nonuniform income distributions. 


\title{
AGGREGATION EFFECTS ON PRICE AND EXPENDITURE ELASTICITIES \\ $\underline{\text { IN A QUADRATIC ALMOST IDEAL DEMAND SYSTEM }}$
}

\author{
Frank T. Denton and Dean C. Mountain
}

McMaster University

\section{INTRODUCTION}

It is well known that utility-based consumer demand equations derived at the micro level do not hold at the macro level, except under highly restrictive assumptions (Stoker 1984, 1986, 1993, for example). In particular, price and expenditure elasticities are subject to "aggregation bias." That is to say, elasticities calculated at mean income, using macro data, are in general different from mean elasticities calculated using micro data. But given that such differences exist, which they obviously do, that leaves open the question of how large they are, and that depends on how income is distributed across consumer units. We explore that question in this paper. To do so our approach is to define a theoretical micro model of consumer expenditure and a corresponding macro model incorporating income distribution parameters, and derive the theoretical differences between elasticities at the two levels. We then calibrate the models by assigning realistic values to their parameters and examine the resulting numerical elasticity differences. In calibrating the macro model we choose parameter values based on actual income distributions for selected countries, thus allowing an exploration of how different degrees of income disparity affect the elasticity differences.

The type of micro model that we use is a quadratic form of the Deaton and Muellbauer 
(1980) Almost Ideal Demand System (the AIDS model). In its original form, the AIDS model is linear in the log of real income, but it can be extended to include polynomial terms of higher order. ${ }^{1}$ In a wide-ranging analysis of U.K. consumer expenditure data, Blundell, Pashardes, and Weber (1993) demonstrated the benefits of using a model with a quadratic real income term added -- a QUAIDS model. (They experimented also with a model that included a cubic term but reported no significant additional benefit.) The QUAIDS model has been used to advantage too by Banks, Blundell, and Lewbel (1997) in a further analysis of U.K. data, and by Denton, Mountain, and Spencer (1999) in an analysis of Canadian expenditure time series.

We employ two micro models, both with QUAIDS structure. In model 1 all households have the same set of parameter values. In model 2 households are divided into two groups, each with a different set of parameter values and a different income distribution. Model 2 allows us to explore the effects of parameter heterogeneity on the macro/micro elasticity differences induced by aggregation.

\section{MODEL 1: ALL HOUSEHOLDS HAVE THE SAME PARAMETER VALUES}

There are $\mathrm{K}$ households in model 1, indexed by $\mathrm{k}$, and I goods, indexed by $\mathrm{i}$ (or by $\mathrm{j}$, if a supplementary index is required). All households have the same utility function and face the same price vector $\mathrm{P}=\left[\begin{array}{llll}\mathrm{p}_{1} & \mathrm{p}_{2} & \ldots & \mathrm{p}_{\mathrm{I}}\end{array}\right]$. Household k's expenditure on good $\mathrm{i}$ is $\mathrm{x}_{\mathrm{ik}}$ and its total expenditure is $\mathrm{x}_{\mathrm{k}}$; thus its budget share for good i is $\mathrm{w}_{\mathrm{ik}}=\mathrm{x}_{\mathrm{ik}} / \mathrm{x}_{\mathrm{k}}$. The QUAIDS micro expenditure model is defined as follows:

$$
\begin{aligned}
& \mathrm{w}_{\mathrm{ik}}=\alpha_{\mathrm{i}}+\sum_{\mathrm{j}=1}^{\mathrm{I}} \gamma_{\mathrm{ij}} \ln \mathrm{p}_{\mathrm{j}}+\beta_{\mathrm{i}} \ln \left(\mathrm{x}_{\mathrm{k}} / \mathrm{q}\right)+\lambda_{\mathrm{i}}\left(\ln \left(\mathrm{x}_{\mathrm{k}} / \mathrm{q}\right)\right)^{2} / \mathrm{Q} \quad(\mathrm{i}=1, \ldots, \mathrm{I}) \\
& \ln \mathrm{q}=\sum_{\mathrm{i}=1}^{\mathrm{I}} \alpha_{\mathrm{i}} \ln \mathrm{p}_{\mathrm{i}}+1 / 2 \sum_{\mathrm{i}=1}^{\mathrm{I}} \sum_{\mathrm{j}=1}^{\mathrm{I}} \gamma_{\mathrm{ij}}\left(\ln \mathrm{p}_{\mathrm{i}}\right)\left(\ln \mathrm{p}_{\mathrm{j}}\right)
\end{aligned}
$$


(3) $\quad \ln Q=\sum_{i=1}^{I} \beta_{i} \ln p_{i}$

Denote aggregate expenditure on good $\mathrm{i}$ by $\mathrm{X}_{\mathrm{i}}$, overall aggregate expenditure by $\mathrm{X}=\Sigma \mathrm{x}_{\mathrm{k}}$, mean overall expenditure by $\overline{\mathrm{X}}=\mathrm{X} / \mathrm{K}$, and the aggregate expenditure share of good $\mathrm{i}$ by $\mathrm{W}_{\mathrm{i}}=\mathrm{X}_{\mathrm{i}} / \mathrm{X}$. The share equation at the micro level can be rewritten as

$$
\mathrm{w}_{\mathrm{ik}}=\alpha_{\mathrm{i}}+\sum_{\mathrm{j}=1}^{\mathrm{I}} \gamma_{\mathrm{ij}} \ln \mathrm{p}_{\mathrm{j}}+\beta_{\mathrm{i}}\left(\ln \left(\mathrm{x}_{\mathrm{k}} / \overline{\mathrm{x}}\right)+\ln (\overline{\mathrm{x}} / \mathrm{q})\right)+\lambda_{\mathrm{i}}\left(\ln \left(\mathrm{x}_{\mathrm{k}} / \overline{\mathrm{x}}\right)+\ln (\overline{\mathrm{x}} / \mathrm{q})\right)^{2} / \mathrm{Q}
$$

and for a household with average income $(\mathrm{x}=\overline{\mathrm{x}})$ this becomes

$$
\mathrm{w}_{\mathrm{ik}}=\alpha_{\mathrm{i}}+\sum_{\mathrm{j}=1}^{\mathrm{I}} \gamma_{\mathrm{ij}} \ln \mathrm{p}_{\mathrm{j}}+\beta_{\mathrm{i}} \ln (\overline{\mathrm{x}} / \mathrm{q})+\lambda_{\mathrm{i}}(\ln (\overline{\mathrm{x}} / \mathrm{q}))^{2} / \mathrm{Q}
$$

The corresponding share equation at the macro level can be obtained by multiplying equation (4) on both sides by $\mathrm{x}_{\mathrm{k}} / \mathrm{X}$ and summing over $\mathrm{k}$ :

$$
\mathrm{W}_{\mathrm{ik}}=\alpha_{\mathrm{i}}^{*}+\sum_{\mathrm{j}=1}^{\mathrm{I}} \gamma_{\mathrm{ij}} \ln \mathrm{p}_{\mathrm{j}}+\beta_{\mathrm{i}} \ln (\overline{\mathrm{x}} / \mathrm{q})+\lambda_{\mathrm{i}}(\ln (\overline{\mathrm{x}} / \mathrm{q}))^{2} / \mathrm{Q}
$$

where $\alpha_{i}^{*}=\alpha_{i}+\beta_{i} g+\lambda_{i} h / Q+2 \lambda_{i} g \ln (\bar{x} / q) / Q$

$$
\begin{aligned}
& \mathrm{g}=\Sigma\left(\mathrm{x}_{\mathrm{k}} / \mathrm{X}\right) \ln \left(\mathrm{x}_{\mathrm{k}} / \overline{\mathrm{x}}\right) \\
& \mathrm{h}=\Sigma\left(\mathrm{x}_{\mathrm{k}} / \mathrm{X}\right)\left(\ln \left(\mathrm{x}_{\mathrm{k}} / \overline{\mathrm{x}}\right)\right)^{2}
\end{aligned}
$$

The important distinction for our purposes is between equation (5) and equation (6). Someone possessing data for individual households can calculate $\mathrm{g}$ and $\mathrm{h}$, and hence estimate either (5) or (6). ${ }^{2}$ Someone possessing only aggregate data and unable to calculate $\mathrm{g}$ and $\mathrm{h}$ can estimate only (6) and the elasticities associated with it. An aggregation problem arises when the equation (6) elasticities are interpreted as if they were equation (5) elasticities.

\section{NORMALIZATIONS}

We introduce some normalizing restrictions. It is an obvious but (for our purposes) important property that elasticities are invariant to the choice of measurement units. With that in mind, and the aim of simplifying the argument, we choose units so that $\overline{\mathrm{x}}=1$ and $\mathrm{p}_{\mathrm{i}}=1, \forall_{\mathrm{i}}$, 
and hence $\mathrm{q}=\mathrm{Q}=1$. At mean income and the given prices that allows us to rewrite equation (5) as

$$
\mathrm{w}_{\mathrm{i}}=\alpha_{\mathrm{i}}
$$

and equation (6) as

$$
\mathrm{W}_{\mathrm{i}}=\alpha_{\mathrm{i}}+\beta_{\mathrm{i}} \mathrm{g}+\lambda_{\mathrm{i}} \mathrm{h}
$$

with $g$ and h now given by $g=\sum_{\mathrm{k}=1}^{\mathrm{K}}\left(\mathrm{x}_{\mathrm{k}} / \mathrm{X}\right) \ln \mathrm{x}_{\mathrm{k}}$ and $\mathrm{h}=\sum_{\mathrm{k}=1}^{\mathrm{K}}\left(\mathrm{x}_{\mathrm{k}} / \mathrm{X}\right)\left(\ln \mathrm{x}_{\mathrm{k}}\right)^{2}$.

The aggregation effects of the income (strictly speaking, expenditure) distribution are dependent on $g$ and $h$, which vanish only if the distribution is uniform. The terms $\beta_{i} g$ and $\lambda_{i} h$ could reinforce or offset each other, depending on their signs. ${ }^{3}$

\section{MICRO AND MACRO ELASTICITIES}

The elasticities derived from the QUAIDS model vary with income and prices. However, for brevity and convenience we adopt in this paper the following definitions: by micro elasticities we shall mean elasticities evaluated at average income using data for individual households; by macro elasticities we shall mean elasticities evaluated at average income using aggregated data. Such elasticities have often been interpreted in the literature as applying to a "representative consumer."

Expenditure elasticities: Let $\varepsilon_{\mathrm{i}}$ denote the micro expenditure elasticity for good $\mathrm{i}$, and let $\bar{\varepsilon}_{\mathrm{i}}$ denote the corresponding macro elasticity. For the normalized model the two elasticities can be expressed as

$$
\begin{aligned}
& \varepsilon_{\mathrm{i}}=1+\beta_{\mathrm{i}} / \mathrm{W}_{\mathrm{i}}=1+\beta_{\mathrm{i}} / \alpha_{\mathrm{i}} \\
& \bar{\varepsilon}_{\mathrm{i}}=1+\beta_{\mathrm{i}} / \mathrm{W}_{\mathrm{i}}=1+\beta_{\mathrm{i}} /\left(\alpha_{\mathrm{i}}+\theta_{\mathrm{i}}\right)
\end{aligned}
$$

where $\theta_{\mathrm{i}}=\beta_{\mathrm{i}} \mathrm{g}+\lambda_{\mathrm{i}} \mathrm{h}$. The difference between the expenditure elasticities can then be written 


$$
b_{i}=\bar{\varepsilon}_{i}-\varepsilon_{i}=\beta_{i}\left(1 /\left(\alpha_{i}+\theta_{i}\right)-1 / \alpha_{i}\right)
$$

Price elasticities:

Let $\eta_{i j}$ and $\bar{\eta}_{i j}$ denote the micro and macro compensated price elasticities, respectively, for good $\mathrm{i}$ with respect to the price of good $\mathrm{j}$. Those elasticities can be written as

$$
\begin{aligned}
& \eta_{i j}=-\delta_{i j}+\gamma_{i j} / \alpha_{i}+\alpha_{j} \\
& \bar{\eta}_{i j}=-\delta_{i j}+\gamma_{i j} /\left(\alpha_{i}+\theta_{i}\right)+\alpha_{j}+\theta_{j}
\end{aligned}
$$

where $\delta_{\mathrm{ij}}=1$ for $\mathrm{i}=\mathrm{j}$ and zero otherwise. The difference between the elasticities is

$$
\mathrm{d}_{\mathrm{ij}}=\bar{\eta}_{\mathrm{ij}}-\eta_{\mathrm{ij}}=\gamma_{\mathrm{ij}}\left(1 /\left(\alpha_{\mathrm{i}}+\theta_{\mathrm{i}}\right)-1 / \alpha_{\mathrm{i}}\right)+\theta_{\mathrm{j}}
$$

\section{CALIBRATION OF MODEL 1: MICRO PARAMETERS}

We calibrate Model 1 by assigning "realistic" values to the micro expenditure and income distribution parameters. Values for the micro parameters are based on econometric estimates in Blundell, Pashardes, and Weber (1993). Under our normalization restrictions $\alpha_{i}=\mathrm{w}_{\mathrm{i}}$, and we take $\mathrm{w}_{\mathrm{i}}$ values (in rounded form) from Table A1 of that paper for the six expenditure categories that the authors identify for estimation. (The seventh category was dropped by the authors because of the singularity of the expenditure system.) Values for the six expenditure and 36 price elasticities, $\varepsilon_{\mathrm{i}}$ and $\eta_{\mathrm{ij}}$, are based on the generalized method of moments estimates in Tables 3A and 3B. Given the $\alpha_{i}$ and $\varepsilon_{i}$ values, the $\beta_{i}$ values can then be calculated. Values for the $\lambda_{i}$ parameters compatible with the other parameter values are based on estimates reported in Table 1A. (Values for the $\gamma_{\mathrm{ij}}$ values can be derived from the other parameter values, but are not required.)

The values that we assign to the micro parameters of model 1 are provided in our Appendix 
Table A1. We have retained, in that table and others, the names of the expenditure categories used by Blundell et al. (food, alcohol, fuel, clothing, transport, and services). However, we do that merely as a reminder that the parameter values we have chosen are "realistic." We emphasize that our calibrated model is not a model estimated by Blundell et al. We have simply used the Blundell at al. results as a guide in calibrating our theoretical model.

\section{INCOME DISTRIBUTION PARAMETERS}

We assign values to $\mathrm{g}$ and $\mathrm{h}$ based on after-tax family income distributions reported in O'Higgins, Schmaus, and Stephenson (1989, Table 2). Values are calculated for seven countries, reflecting a wide range of income distributions. Strictly speaking the $g$ and $h$ values should be based on distributions of expenditure rather than income but international data for expenditure distributions are not readily available. Approximating them by income distributions seems quite adequate for our purposes. For convenience we refer to "income distributions" in what follows.

The distributions in O'Higgins, Schmaus, and Stephenson are in the form of quintile group shares. Let $\mathrm{S}_{\mathrm{r}}$ be the proportionate share of the $\mathrm{r}^{\text {th }}$ quintile group and assume (as an approximation) that all families in the group have the same income. If the normalization restriction $\overline{\mathrm{x}}=1$ is imposed for the distribution as a whole, then it is easily shown that $\mathrm{g}=\Sigma \mathrm{S}_{\mathrm{r}} \ln \left(5 \mathrm{~S}_{\mathrm{r}}\right)$ and $\mathrm{h}=\Sigma \mathrm{S}_{\mathrm{r}}\left(\ln \left(5 \mathrm{~S}_{\mathrm{r}}\right)\right)^{2}$. (We did some experimental calculations to see whether having more groups to work with would have made much difference: we created, by interpolation, up to 20 quantile groups and redid the calculations. The results were almost identical to the original ones.)

The calculated values of $\mathrm{g}$ and $\mathrm{h}$ are provided in Table 1 for the seven countries. Lower values imply less inequality in a distribution, higher values more inequality. The range is from 
$\mathrm{g}=0.123, \mathrm{~h}=0.242$, for Sweden, to $\mathrm{g}=0.229, \mathrm{~h}=0.456$, for Germany. The median country is Canada, with values $\mathrm{g}=0.171$ and $\mathrm{h}=0.321$.

\section{EFFECTS OF INCOME DISTRIBUTION ON MODEL 1 ELASTICITY DIFFERENCES}

Having calibrated Model 1 at the micro level we now embed the model in each of the seven income distributions, calculate the resulting macro elasticities under each distribution (using equations (10) and (13)), and compare them with the micro elasticities to evaluate the effects of aggregation. The macro expenditure and own-price elasticities are reported in Table 2, along with the corresponding micro elasticities and the differences between the two. The full set of price elasticities is reported in Table 3 but to save space the macro elasticities are shown in that table only for the two most extreme income distributions, those of Sweden and Germany.

It is theoretically possible for aggregation to change the sign of an elasticity but there are no instances of that in either table. It is possible too for a category of goods that is expenditureelastic or price-elastic (elasticity greater than one, ignoring sign) to become inelastic, but again that does not happen. The largest macro/micro differences between expenditure elasticities are for alcohol, which also has the highest elasticities: for German and Swedish income distributions (which bound the range) the macro elasticities are 2.006 and 2.120, respectively, compared with a micro elasticity of 2.290. Aside from alcohol, the largest macro/micro difference between expenditure elasticities is .043 (food, with the German income distribution), and in most cases the differences are much smaller, or even zero. Among price elasticities the largest difference is again for alcohol: the macro own-price elasticity with the German income distribution is -1.417, compared with a micro elasticity of -1.580 , a difference of 0.163 , or 10.3 percent of the micro elasticity. Omitting alcohol, the price elasticity differences in Table 3 range from zero to 0.091 . 
Our overall reading of the evidence in Tables 2 and 3 is that elasticity differences resulting strictly from aggregation can certainly vary but are generally likely to be rather small, regardless of the income distribution.

\section{MODEL 2: DIFFERENT GROUPS WITH DIFFERENT PARAMETER VALUES}

Model 1 assumes homogeneity of parameters across the population of consuming units. We now define Model 2, in which the population is divided into groups; parameters are the same for all units within a group but differ from one group to another. Income distributions also differ from group to group. Model 2 allows us to investigate the effects of parameter heterogeneity interacting with income distribution on the elasticity differences resulting from aggregation. To that end we calibrate Model 2, derive the micro and macro elasticities for each group, and then combine the group elasticities to obtain overall elasticities.

Let the population be divided into groups, indexed by $\mathrm{a}=1, \ldots, \mathrm{m}$, and denote the elasticities for the $a^{\text {th }}$ group by $\varepsilon_{\mathrm{ia}}, \eta_{\mathrm{ija}}$, at the micro level, and by $\bar{\varepsilon}_{\mathrm{ia}}, \bar{\eta}_{\mathrm{ija}}$, at the macro level. Denote further the corresponding elasticities for all groups combined by $\varepsilon_{\mathrm{i}}, \eta_{\mathrm{ij}}$, and $\bar{\varepsilon}_{\mathrm{i}}, \bar{\eta}_{\mathrm{ij}}$. Prices are the same for all groups. The micro elasticities for group a are calculated at the group's mean income, based on a straightforward adaptation of equations (9) and (12). Similarly, the macro elasticities for the group are calculated by adapting equations (10) and (13). (If the income normalizing restriction is used it should be used separately within each group, and then discarded; mean income will differ from group to group, and normalization of it across groups would be inappropriate. The final elasticity values will be the same, of course, whether or not the normalization is adopted.)

The macro elasticities for all groups combined are weighted combinations of the group- 
specific macro elasticities. Assume that a group's mean income (not normalized) varies proportionately with overall mean income: $\overline{\mathrm{x}}_{\mathrm{a}} / \overline{\mathrm{x}}$ is constant for all a. It is then straightforward to show that the overall macro elasticities are given by

$$
\begin{aligned}
& \bar{\varepsilon}_{\mathrm{i}}=\sum_{\mathrm{a}} \xi_{\mathrm{ia}} \bar{\varepsilon}_{\mathrm{ia}} \\
& \bar{\eta}_{\mathrm{ij}}=\sum_{\mathrm{a}} \xi_{\mathrm{ia}} \bar{\eta}_{\mathrm{ija}}
\end{aligned}
$$

where $\xi_{\mathrm{ia}}=\sum_{\mathrm{a}}\left(\mathrm{W}_{\mathrm{ia}} \mathrm{S}_{\mathrm{a}} / \sum_{\mathrm{a}^{\prime}} \mathrm{W}_{\mathrm{ia}^{\prime}} \mathrm{S}_{\mathrm{a}^{\prime}}\right), \quad \mathrm{S}_{\mathrm{a}}=\mathrm{X}_{\mathrm{a}} / \mathrm{X}$ is group a's share of total income, and $\mathrm{W}_{\mathrm{ia}}=\mathrm{X}_{\mathrm{ia}} / \mathrm{X}_{\mathrm{a}}$ is the aggregate expenditure share of good $\mathrm{i}$ in group a. Similarly, the micro elasticities for all groups combined can be defined as weighted combinations of the groupspecific micro elasticities:

$$
\begin{aligned}
& \varepsilon_{i}=\sum_{a} \xi_{i a}^{\prime} \varepsilon_{i a} \\
& \eta_{i j}=\sum_{a} \xi_{i a}^{\prime} \eta_{i j a}
\end{aligned}
$$

where $\xi_{\mathrm{ia}}^{\prime}$ is equal to $\xi_{\mathrm{ia}}$ with the group-specific macro expenditure shares, $\mathrm{W}_{\mathrm{ia}}$, replaced by the corresponding micro expenditure shares, $\mathrm{w}_{\mathrm{ia}}$.

The micro elasticities for all groups combined are interpreted as those of a composite "representative consumer," just as the micro elasticities for the groups are interpreted as relating to group-specific "representative consumers." It is easily shown that the micro elasticities defined by equations (17) and (18) are consistent with the macro elasticities defined by equations (15) and (16) by noting that they are the same when all of the group-specific income distributions are uniform $\left(g_{a}=h_{a}=0\right)$. As with model 1 , any differences are thus a consequence of aggregation in the presence of nonuniform distributions. 
The groups in model 2 could be defined as any divisions of the population that are of interest: income categories, regions, demographic groups, etc. If one were specifying an econometric model by adapting the QUAIDS model of equations (1) - (3) one might allow all parameters to vary, say, or only the intercepts, or only the intercepts and the $\beta$ and $\lambda$ parameters. Parameter variation could be provided for by appropriate incorporation of dummy variables. However, our concern here is with theoretical differences in elasticities, not with practical issues of econometric specification.

\section{CALIBRATION OF MODEL 2}

Model 2, like Model 1, is calibrated using parameter estimates from Blundell, Pashardes, and Weber (1993) as a starting point. We specify two groups $(\mathrm{m}=2)$, each with the same share of total income $\left(\mathrm{S}_{\mathrm{a}}=0.5\right)$, choose parameter values for the two that differ widely, and assign to each group one of the two extreme income distributions, those of Sweden and Germany. A high degree of heterogeneity across the groups is thus provided for.

A convenient way of introducing widely differing parameter values into the model is to use the estimated expenditure and own-price elasticities for the lowest and highest income quantile groups shown in Table 3 of Blundell et al. (We do not require cross-price elasticities for subsequent calculations.) Accordingly, we assign to group 1 the elasticities for the bottom 5 percent of households and to group 2 the elasticities for the top 10 percent. (Only uncompensated price elasticities were available for income quantile groups; we adjusted them to make them resemble compensated elasticities, based on the relationships between compensated and uncompensated elasticities for all income levels combined, shown elsewhere in the table.) Values for $\alpha_{\mathrm{ia}}$ (equal to the expenditure shares $\mathrm{w}_{\mathrm{ia}}$ ) are then set arbitrarily, but in such a way 
as to allow substantial differences between the two groups, and so that the implied expenditure shares will reflect roughly the income differences between the two. (Group 1 is given a much higher value for food but a much lower value for services, for example.) With $\alpha$ and $\varepsilon$ set for the two groups the corresponding values for $\beta$ can be calculated, as before. The $\lambda$ parameters for group 1 are set equal to half the model 1 values; for group 2 they are set equal to twice the model 1 values, thus imposing much more curvature on the implied Engel curves in group 2 than in group 1.

The calibration values for model 2 at the micro level are displayed in Appendix Table A2. As can be seen, they differ markedly between the two groups, reflecting our attempt to impose a high degree of parameter heterogeneity on the model but still choose values that are "realistic."

\section{EFFECTS OF INCOME DISTRIBUTION ON MODEL 2 ELASTICITY DIFFERENCES}

Calculated values of macro elasticities for the calibrated version of model 2 are shown in Table 4, and compared with the micro elasticities. The calculations are based on all four possible combinations of the Swedish (SW) and German (GE) income distributions, as represented by their $\mathrm{g}$ and $\mathrm{h}$ parameters: $\mathrm{SW}$ in both groups 1 and 2; GE in both groups; $\mathrm{SW}$ in group 1, GE in group 2; and GE in group 1, SW in group 2.

The results reported in Table 4 are broadly similar to those of Tables 2 and 3 . The largest of the macro/micro elasticity differences is 0.151 (ignoring sign), the expenditure elasticity for alcohol when both groups have the GE distribution. (Measured against the micro elasticity of 1.923 that represents a proportionate difference of 7.9 percent.) Most of the other differences are much smaller. The assignment of income distributions affects the macro elasticities, as one would expect, but the range of variation is generally narrow. Based on the evidence of our 
calculations it appears that parameter heterogeneity does not alter much the aggregation effects of income distribution. One could specify more than two groups but it seems unlikely that that would change the general conclusion, given that we have allowed our two groups to have widely differing parameter values.

\section{ELASTICITY DIFFERENCES AND STANDARD ERRORS}

It is of interest to consider how the macro/micro differences relate to the kinds of probability statements that one might make in interpreting econometric estimates of elasticities. While our theoretical models themselves obviously provide no way of generating standard errors we have based the calibration of the models on econometric estimates taken from the Blundell et al. study, and we can therefore use the standard errors from that study for guidance. We have taken two sets of standard errors for estimated expenditure and price elasticities: those reported by Blundell et al. for the general method of moments estimates in their Table 3, parts A and B, which we refer to as data set I, and those reported in Table 4, parts A and B, which we refer to as data set II. Mean standard errors calculated for the two data sets are shown in our Table 5 for all elasticities combined, for expenditure elasticities alone, for all price elasticities, and for ownprice and cross-price elasticities. Mean macro/micro elasticity differences from the calculations based on our calibrated versions of models 1 and 2 with Swedish and German income distributions are shown also in the table, and expressed as ratios to the mean standard errors.

The mean standard errors are labeled $\overline{\mathrm{s}}$ and the mean elasticity differences $\overline{\mathrm{d}}$. An examination of the $\overline{\mathrm{d}} / \overline{\mathrm{s}}$ ratios in Table 5 shows them to be generally small, whichever of the five elasticity categories one looks at. The maximum ratio in the table is about 0.35 , the minimum 0.07 . These results must be interpreted as only rough indicators but they do suggest 
that, on average, macro/micro differences are likely to be much smaller than any confidence interval that might be placed around an estimated elasticity.

\section{CONCLUSION}

We find the results presented in this paper somewhat reassuring for anyone who must work with aggregate data (in particular with time series, where the use of micro data for model estimation is most often not an option). A nonuniform distribution of income certainly induces aggregation effects on expenditure and price elasticities but the evidence suggests that such effects may not be as large as one might have thought, even for income distributions that depart as much from uniformity as those of Germany and the U.S. It seems likely that aggregation effects on the econometric estimates of elasticities will typically be dominated by other effects, including sampling variation, choice of estimation method, measurement error, and model misspecification. $^{4}$ 


\section{FOOTNOTES}

1. For a simplified analysis of aggregation effects using the basic linear AIDS model see Denton and Mountain, 2001.

2. We are not concerned in the present theoretical argument with changes over time in the distribution parameters $\mathrm{g}$ and $\mathrm{h}$ but we note in passing that they are insensitive to "mean scaling" and may therefore have some degree of stability (see Lewbel 1990, 1991, 1992).

3. The normalizing restrictions on income (as we shall now refer to total expenditure) and prices are strictly for convenience in the theoretical derivation of elasticities, the calculated values of which would be the same whether or not the restrictions were imposed. We are not suggesting the use of such restrictions for the specification of a model for econometric estimation. Note too that the choice of units is time dependent; except in the unlikely event that prices and mean income were perfectly stable different choices would have to be made at different points in time. However, that does not affect the present theoretical derivations.

4. We note in that regard that published estimates of elasticities show a wide range of variation. See Denton, Mountain, and Spencer (1999) for a survey of estimates from a number of studies and discussion of the large differences among them. 


\section{$\underline{\text { REFERENCES }}$}

Banks, James, Richard Blundell, and Arthur Lewbel (1997), “Quadratic Engel Curves and Consumer Demand," Review of Economics and Statistics, 79, 527-39.

Blundell, Richard, Panos Pashardes, and Guglielmo Weber (1993), "What Do We Learn About Consumer Demand Patterns from Micro Data?," American Economic Review, 83, 570-97.

Deaton, Angus S. and John Muellbauer (1980), "An Almost Ideal Demand System," American Economic Review, 70, 312-26.

Denton, Frank T. and Dean C. Mountain (2001), "Income Distribution and Aggregation/Disaggregation Biases in the Measurement of Consumer Demand Elasticities," Economics Letters, 73, 21-8.

Denton, Frank T., Dean C. Mountain, and Byron G. Spencer (1999), “Age, Trend, and Cohort Effects in a Macro Model of Canadian Expenditure Patterns," Journal of Business and Economic Statistics, 17, 430-43.

Lewbel, Arthur (1990), "Income Distribution Movements and Aggregate Money Illusion," Journal of Econometrics, 43, 35-42.

Lewbel, Arthur (1991), "The Rank of Demand Systems: Theory and Nonparametric Estimation," Econometrica, 59, 711-30.

Lewbel, Arthur (1992), “Aggregation with Log-Linear Models,” Review of Economic Studies, $59,635-42$.

O’Higgins, Michael, Guenther Schmaus, and Geoffrey Stephenson (1989), "Income Distribution and Redistribution: A Microdata Analysis for Seven Countries," Review of Income and Wealth, 35, 107-31. 
Stoker, Thomas M. (1984), "Completeness, Distribution Restrictions, and the form of Aggregate Functions," Econometrica, 52, 887-907.

Stoker, Thomas M. (1986), "Simple Tests of Distributional Effects on Macroeconomic Equations," Journal of Political Economy, 94, 763-95.

Stoker, Thomas M. (1993), "Empirical Approaches to the Problem of Aggregation Over Individuals," Journal of Economic Literature, 31, 1827-74. 
TABLE 1: INCOME DISTRIBUTION PARAMETERS FOR SEVEN COUNTRIES

\begin{tabular}{lcc}
\hline & $\mathrm{g}$ & $\mathrm{h}$ \\
\hline Sweden & 0.123 & 0.242 \\
Norway & 0.142 & 0.259 \\
Israel & 0.166 & 0.313 \\
Canada & 0.171 & 0.321 \\
United Kingdom & 0.172 & 0.321 \\
United States & 0.204 & 0.367 \\
Germany & 0.229 & 0.456 \\
\hline
\end{tabular}

Note: Calculations are by the authors, based on after-tax family income quintile shares provided in Table 2 of O'Higgins, Schmaus, and Stephenson (1989). 
TABLE 2: MACRO/MICRO DIFFERENCES IN EXPENDITURE AND OWN-PRICE ELASTICITIES: MODEL 1, WITH SEVEN ALTERNATIVE INCOME DISTRIBUTIONS

\begin{tabular}{|c|c|c|c|c|c|c|c|c|c|c|c|c|}
\hline & \multicolumn{6}{|c|}{ Expenditure elasticity } & \multicolumn{6}{|c|}{ Own-price elasticity } \\
\hline & Food & Alcohol & Fuel & Clothing & Transport & $\begin{array}{c}\text { Service } \\
\mathrm{S} \\
\end{array}$ & Food & Alcohol & Fuel & Clothing & Transport & Services \\
\hline Micro & 0.61 & 2.29 & 0.84 & 0.92 & 1.2 & 1.45 & -0.4 & -1.58 & -0.45 & -0.53 & -0.48 & -0.55 \\
\hline \multicolumn{13}{|l|}{ Macro } \\
\hline Sweden & .588 & 2.120 & .854 & .914 & 1.191 & 1.450 & -.352 & -1.484 & -.482 & -.508 & -.487 & -.550 \\
\hline Norway & .585 & 2.097 & .854 & .913 & 1.190 & 1.447 & -.352 & -1.471 & -.484 & -.506 & -.487 & -.551 \\
\hline Israel & .580 & 2.070 & .857 & .912 & 1.189 & 1.448 & -.352 & -1.455 & -.490 & -.501 & -.488 & -.551 \\
\hline Canada & .579 & 2.065 & .857 & .911 & 1.189 & 1.448 & -.352 & -1.452 & -.491 & -.500 & -.489 & -.551 \\
\hline United Kingdom & .579 & 2.064 & .857 & .911 & 1.188 & 1.448 & -.352 & -1.451 & -.491 & -.500 & -.489 & -.551 \\
\hline United States & .572 & 2.030 & .859 & .910 & 1.187 & 1.446 & -.352 & -1.431 & -.496 & -.495 & -.490 & -.552 \\
\hline Germany & .567 & 2.006 & .864 & .907 & 1.185 & 1.450 & -.352 & -1.417 & -.506 & -.485 & -.491 & -.550 \\
\hline \multicolumn{13}{|l|}{$\begin{array}{l}\text { Difference } \\
\text { (macro-micro) }\end{array}$} \\
\hline Sweden & -.022 & -.170 & .014 & -.006 & -.009 & .000 & -.002 & .096 & -.032 & .022 & -.007 & .000 \\
\hline Norway & -.025 & -.193 & .014 & -.007 & -.010 & -.003 & -.002 & .109 & -.034 & .024 & -.007 & -.001 \\
\hline Israel & -.030 & -.220 & .017 & -.008 & -.011 & -.002 & -.002 & .125 & -.040 & .029 & -.008 & -.001 \\
\hline Canada & -.031 & -.225 & .017 & -.009 & -.011 & -.002 & -.002 & .128 & -.041 & .030 & -.009 & -.001 \\
\hline United Kingdom & -.031 & -.226 & .017 & -.009 & -.012 & -.002 & -.002 & .129 & -.041 & .030 & -.009 & -.001 \\
\hline United States & -.038 & -.260 & .019 & -.010 & -.013 & -.004 & -.002 & .149 & -.046 & .035 & -.010 & -.002 \\
\hline Germany & -.043 & -.284 & .024 & -.013 & -.015 & .000 & -.002 & .163 & -.056 & .045 & -.011 & .000 \\
\hline
\end{tabular}




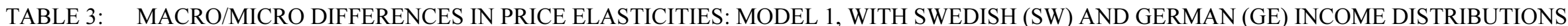

\begin{tabular}{|c|c|c|c|c|c|c|c|c|c|c|c|c|c|}
\hline & & \multicolumn{2}{|c|}{ Food } & \multicolumn{2}{|c|}{ Alcohol } & \multicolumn{2}{|c|}{ Fuel } & \multicolumn{2}{|c|}{ Clothing } & \multicolumn{2}{|c|}{ Transport } & \multicolumn{2}{|c|}{ Services } \\
\hline & & SW & $\mathrm{GE}$ & SW & $\mathrm{GE}$ & SW & $\mathrm{GE}$ & SW & $\mathrm{GE}$ & SW & GE & SW & $\mathrm{GE}$ \\
\hline \multirow[t]{3}{*}{ Food: } & micro & -.350 & -.350 & .120 & .120 & -.010 & -.010 & .030 & .030 & .140 & .140 & .130 & .130 \\
\hline & macro & -.352 & -.352 & .133 & .145 & -.008 & -.006 & .019 & .009 & .146 & .151 & .131 & .131 \\
\hline & difference & -.002 & -.002 & .013 & .025 & .002 & .004 & -.011 & -.021 & .006 & .011 & .001 & .001 \\
\hline \multirow[t]{3}{*}{ Alcohol: } & micro & .630 & .630 & -1.580 & -1.580 & .780 & .780 & .260 & .260 & .250 & .250 & .020 & .020 \\
\hline & macro & .574 & .533 & -1.484 & -1.417 & .695 & .640 & .232 & .211 & .249 & .250 & .033 & .042 \\
\hline & difference & -.056 & -.097 & .096 & .163 & -.085 & -.140 & -.028 & -.049 & -.001 & .000 & .013 & .022 \\
\hline \multirow[t]{3}{*}{ Fuel: } & micro & -.050 & -.050 & .620 & .620 & -.450 & -.450 & .050 & .050 & -.330 & -.330 & -.230 & -.230 \\
\hline & macro & -.035 & -.026 & .584 & .558 & -.482 & -.506 & .047 & .044 & -.279 & -.239 & -.200 & -.178 \\
\hline & difference & .015 & .024 & -.036 & -.062 & -.032 & -.056 & -.003 & -.006 & .051 & .091 & .030 & .052 \\
\hline \multirow[t]{3}{*}{ Clothing: } & micro & .120 & .120 & .170 & .170 & .040 & .040 & -.530 & -.530 & -.100 & -.100 & -.260 & -.260 \\
\hline & macro & .083 & .049 & .188 & .206 & .044 & .048 & -.508 & -.485 & -.114 & -.129 & -.290 & -.320 \\
\hline & difference & -.037 & -.071 & .018 & .036 & .004 & .008 & .022 & .045 & -.014 & -.029 & -.030 & -.060 \\
\hline \multirow[t]{3}{*}{ Transport: } & micro & .270 & .270 & .100 & .100 & -.160 & -.160 & -.060 & -.060 & -.480 & -.480 & .270 & .270 \\
\hline & macro & .255 & .241 & .109 & .117 & -.142 & -.128 & -.060 & -.061 & -.487 & -.491 & .264 & .258 \\
\hline & difference & -.015 & -.029 & .009 & .017 & .018 & .032 & .000 & -.001 & -.007 & -.011 & -.006 & -.012 \\
\hline \multirow[t]{3}{*}{ Services: } & micro & .380 & .380 & .010 & .010 & -.160 & -.160 & -.230 & -.230 & .400 & .400 & -.550 & -.550 \\
\hline & macro & .361 & .345 & .021 & .030 & -.152 & -.146 & -.237 & -.244 & .408 & .415 & -.550 & -.550 \\
\hline & difference & -.019 & -.035 & .011 & .020 & .008 & .014 & -.007 & -.014 & .008 & .015 & .000 & .000 \\
\hline
\end{tabular}


TABLE 4: MACRO/MICRO DIFFERENCES IN EXPENDITURE AND OWN-PRICE ELASTICITIES: MODEL 2, WITH FOUR ALTERNATIVE PAIRS OF INCOME DISTRIBUTIONS BASED ON SWEDISH (SW) AND GERMAN (GE) DISTRIBUTIONS

\begin{tabular}{|c|c|c|c|c|c|c|c|c|c|c|c|c|}
\hline & \multicolumn{6}{|c|}{ Expenditure elasticity } & \multicolumn{6}{|c|}{ Own-price elasticity } \\
\hline & Food & Alcohol & Fuel & Clothing & Transport & Services & Food & Alcohol & Fuel & Clothing & Transport & Services \\
\hline Micro & 0.56 & 1.923 & 0.922 & 1.122 & 1.22 & 1.268 & -0.393 & -1.435 & -0.522 & -0.453 & -0.61 & -0.516 \\
\hline \multicolumn{13}{|l|}{ Macro } \\
\hline $\mathrm{SW}$ in both groups & .531 & 1.835 & .931 & 1.130 & 1.209 & 1.278 & -.392 & -1.380 & -.564 & -.434 & -.615 & -.517 \\
\hline GE in both groups & .502 & 1.772 & .938 & 1.139 & 1.201 & 1.287 & -.390 & -1.339 & -.592 & -.413 & -.619 & -.518 \\
\hline $\mathrm{SW}$ in group $1, \mathrm{GE}$ in group 2 & .511 & 1.799 & .938 & 1.141 & 1.200 & 1.299 & -.392 & -1.357 & -.594 & -.405 & -.618 & -.503 \\
\hline $\mathrm{GE}$ in group $1, \mathrm{SW}$ in group 2 & .523 & 1.806 & .931 & 1.128 & 1.210 & 1.267 & -.390 & -1.361 & -.562 & -.441 & -.616 & -.530 \\
\hline \multicolumn{13}{|l|}{ Difference (macro-micro) } \\
\hline $\mathrm{SW}$ in both groups & -.029 & -.088 & .009 & .008 & -.011 & .010 & .001 & .055 & -.042 & .019 & -.005 & -.001 \\
\hline GE in both groups & -.058 & -.151 & .016 & .017 & -.019 & .019 & .003 & .096 & -.070 & .040 & -.009 & -.002 \\
\hline $\mathrm{SW}$ in group $1, \mathrm{GE}$ in group 2 & -.049 & -.124 & .016 & .019 & -.020 & .031 & .001 & .078 & -.072 & .048 & -.008 & .013 \\
\hline $\mathrm{GE}$ in group $1, \mathrm{SW}$ in group 2 & -.037 & -.117 & .009 & .006 & -.010 & -.001 & .003 & .074 & -.040 & .012 & -.006 & -.014 \\
\hline
\end{tabular}


TABLE 5: COMPARISONS OF MEAN DIFFERENCES BETWEEN MACRO AND MICRO ELASTICITIES, BASED ON SWEDISH (SW) AND GERMAN (GE) INCOME DISTRIBUTIONS, WITH MEAN STANDARD ERRORS FROM TWO DATA SETS

\begin{tabular}{|c|c|c|c|c|c|}
\hline & $\begin{array}{c}\text { All } \\
\text { elasticities }\end{array}$ & $\begin{array}{l}\text { Expenditure } \\
\text { elasticities }\end{array}$ & $\begin{array}{l}\text { All price } \\
\text { elasticities }\end{array}$ & $\begin{array}{l}\text { Own-price } \\
\text { elasticities }\end{array}$ & $\begin{array}{l}\text { Cross-price } \\
\text { elasticities }\end{array}$ \\
\hline \multicolumn{6}{|c|}{ Mean standard errors $(\overline{\mathrm{s}})$ of estimated elasticities } \\
\hline Data set I & .119 & .193 & .106 & .133 & .101 \\
\hline Data set II & .162 & .370 & .127 & .147 & .123 \\
\hline \multicolumn{6}{|c|}{ Comparisons for model 1 based on SW distribution } \\
\hline Mean macro/micro difference $(\overline{\mathrm{d}})$ & .022 & .037 & .020 & .026 & .018 \\
\hline Ratio $\overline{\overline{\mathrm{d}}} / \overline{\mathrm{s}}$ with $\overline{\mathrm{s}}$ from data set I & .185 & .192 & .189 & .195 & .178 \\
\hline Ratio $\overline{\mathrm{d}} / \overline{\mathrm{s}}$ with $\overline{\mathrm{s}}$ from data set II & .136 & .100 & .157 & .177 & .146 \\
\hline \multicolumn{6}{|c|}{ Comparisons for model 1 based on GE distribution } \\
\hline Mean macro/micro difference $(\overline{\mathrm{d}})$ & .039 & .063 & .035 & .046 & .033 \\
\hline Ratio $\overline{\overline{\mathrm{d}}} / \overline{\mathrm{s}}$ with $\overline{\mathrm{s}}$ from data set I & .328 & .326 & .330 & .346 & .327 \\
\hline Ratio $\overline{\mathrm{d}} / \overline{\mathrm{s}}$ with $\overline{\mathrm{s}}$ from data set II & .241 & .170 & .276 & .313 & .268 \\
\hline \multicolumn{6}{|c|}{ Comparisons for model 2 based on SW/SW distribution } \\
\hline Mean macro/micro difference $(\overline{\mathrm{d}})$ & -- & .026 & -- & .020 & -- \\
\hline Ratio $\overline{\overline{\mathrm{d}}} / \overline{\mathrm{s}}$ with $\overline{\mathrm{s}}$ from data set I & -- & .135 & -- & .150 & -- \\
\hline Ratio $\overline{\mathrm{d}} / \overline{\mathrm{s}}$ with $\overline{\mathrm{s}}$ from data set II & -- & .070 & -- & .136 & -- \\
\hline \multicolumn{6}{|c|}{ Comparisons for model 2 based on GE/GEdistribution } \\
\hline 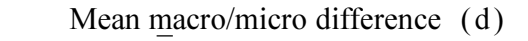 & -- & .047 & -- & .037 & -- \\
\hline Ratio $\overline{\overline{\mathrm{d}}} / \overline{\mathrm{s}}$ with $\overline{\mathrm{s}}$ from data set I & -- & .244 & -- & .278 & -- \\
\hline Ratio $\overline{\mathrm{d}} / \overline{\mathrm{s}}$ with $\overline{\mathrm{s}}$ from data set II & -- & .127 & -- & .252 & -- \\
\hline \multicolumn{6}{|c|}{ Comparisons for model 2 based on SW/GE distribution } \\
\hline Mean macro/micro difference $(\mathrm{d})$ & -- & .043 & -- & .037 & -- \\
\hline Ratio $\overline{\overline{\mathrm{d}}} / \overline{\mathrm{s}}$ with $\overline{\mathrm{s}}$ from data set I & -- & .223 & -- & .278 & -- \\
\hline Ratio $\overline{\mathrm{d}} / \overline{\mathrm{s}}$ with $\overline{\mathrm{s}}$ from data set II & -- & .116 & -- & .252 & -- \\
\hline \multicolumn{6}{|c|}{ Comparisons for model 2 based on GE/SW distribution } \\
\hline 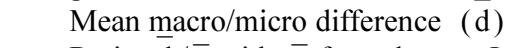 & -- & .030 & -- & .025 & -- \\
\hline Ratio $\underline{\overline{\mathrm{d}}} / \overline{\mathrm{s}}$ with $\overline{\mathrm{s}}$ from data set I & -- & .155 & -- & .188 & -- \\
\hline Ratio $\overline{\mathrm{d}} / \overline{\mathrm{s}}$ with $\overline{\mathrm{s}}$ from data set II & -- & .081 & -- & .170 & -- \\
\hline
\end{tabular}

Note: Standard error data sets I and II are from Table 3 (parts A and B) and Table 4 (parts A and B), respectively, of Blundell, Pashardes, and Weber (1993). Mean macro/micro differences are means of absolute values. For model 2, SW/SW means Swedish income distribution in both groups, SW/GE means Swedish distribution in group 1, German distribution in group 2, and so on. 


\section{APPENDIX: PARAMETER VALUES USED IN CALIBRATION}

TABLE A1: CALIBRATION OF MICRO MODEL 1

\begin{tabular}{|c|c|c|c|c|c|c|}
\hline & Food & Alcohol & Fuel & Clothing & Transport & Services \\
\hline \multicolumn{7}{|l|}{ Share equation parameters } \\
\hline$\alpha_{\mathrm{i}}$ & .35 & .07 & .08 & .10 & .18 & .12 \\
\hline$\beta_{\mathrm{i}}$ & -.1365 & .0903 & -.0128 & -.008 & .036 & .054 \\
\hline$\lambda_{\mathrm{i}}$ & -.008 & -.002 & .037 & -.026 & .015 & -.027 \\
\hline Expenditure elasticity $\left(\varepsilon_{\mathrm{i}}\right)$ & 0.61 & 2.29 & 0.84 & 0.92 & 1.2 & 1.45 \\
\hline \multicolumn{7}{|l|}{ Price elasticities $\left(\eta_{\mathrm{ij}}\right)$} \\
\hline Food & -.35 & .12 & -.01 & .03 & .14 & .13 \\
\hline Alcohol & .63 & -1.58 & .78 & .26 & .25 & .02 \\
\hline Fuel & -.05 & .62 & -.45 & .05 & -.33 & -.23 \\
\hline Clothing & .12 & .17 & .04 & -.53 & -.10 & -.26 \\
\hline Transport & .27 & .10 & -.16 & -.06 & -.48 & .27 \\
\hline Services & .38 & .01 & -.16 & -.23 & .40 & -.55 \\
\hline
\end{tabular}

TABLE A2: CALIBRATION OF MICRO MODEL 2

\begin{tabular}{|c|c|c|c|c|c|c|}
\hline & Food & Alcohol & Fuel & Clothing & Transport & Services \\
\hline \multicolumn{7}{|c|}{ Group 1} \\
\hline$\alpha_{i}$ & .40 & .04 & .11 & .12 & .13 & .07 \\
\hline$\beta_{\mathrm{i}}$ & -.0840 & .0552 & -.0539 & .0564 & -.0312 & .1120 \\
\hline$\lambda_{\mathrm{i}}$ & -.004 & -.001 & .018 & -.013 & .007 & -.013 \\
\hline$\varepsilon_{\mathrm{i}}$ & .79 & 2.38 & .51 & 1.47 & .76 & 2.60 \\
\hline$\eta_{\mathrm{ii}}$ & -.46 & -1.64 & -.61 & -.38 & -.34 & -.50 \\
\hline \multicolumn{7}{|c|}{ Group 2} \\
\hline$\alpha_{i}$ & .20 & .10 & .05 & .08 & .23 & .17 \\
\hline$\beta_{i}$ & -.1800 & .0740 & .0415 & -.0320 & .1104 & -.0476 \\
\hline$\lambda_{\mathrm{i}}$ & -.016 & -.004 & .074 & -.052 & .030 & -.054 \\
\hline$\varepsilon_{\mathrm{i}}$ & .10 & 1.74 & 1.83 & .60 & 1.48 & .72 \\
\hline$\eta_{\mathrm{ii}}$ & -.11 & -1.33 & -.35 & -.53 & -.71 & -.54 \\
\hline
\end{tabular}


http://socserv2.mcmaster.ca/ qsep. The Research Report series provides a vehicle for distributing the results of studies undertaken by QSEP associates. Authors take full responsibility for all expressions of opinion.

No. 351: Describing Disability among High and Low Income Status

Older Adults in Canada

No. 352: $\quad$ Some Demographic Consequences of Revising the Definition of 'Old' to Reflect Future Changes in Life Table Probabilities

No. 353: The Correlation Between Husband's and Wife's Education: Canada, 1971-1996

No. 354: The Effect of Marginal Tax Rates on Taxable Income: A Panel Study of the 1988 Tax Flattening in Canada

No. 355: Population Change and the Requirements for Physicians: The Case of Ontario

No. 356: $\quad 2 \frac{1}{2}$ Proposals to Save Social Security

No. 357: The Consequences of Caregiving: Does Employment Make A Difference?

No. 358: Exploring the Effects of Population Change on the Costs of Physician Services

No. 359: Reflexive Planning for Later Life: A Conceptual Model and Evidence from Canada
P. Raina

M. Wong

L.W. Chambers

M. Denton

A. Gafni

F.T. Denton

B.G. Spencer

L. Magee

J. Burbidge

L. Robb

M.-A. Sillamaa

M.R. Veall

F.T. Denton

A. Gafni

B.G. Spencer

D. Fretz

M.R. Veall

C.L. Kemp

C.J. Rosenthal

F.T. Denton

A. Gafni

B.G. Spencer

M.A. Denton

S. French

A. Gafni

A. Joshi

C. Rosenthal

S. Webb

F.T. Denton

C.H. Feaver

B.G. Spencer

J. Zelmer

No. 361: Linear Public Goods Experiments: A Meta-Analysis 
No. 362: The Timing and Duration of Women's Life Course Events: A Study of Mothers With At Least Two Children

No. 363: Age-Gapped and Age-Condensed Lineages: Patterns of Intergenerational Age Structure among Canadian Families

No. 364: The Education Premium in Canada and the United States

No. 365: Student Enrolment and Faculty Recruitment in Ontario: The Double Cohort, the Baby Boom Echo, and the Aging of University Faculty

No. 366: The Economic Well-Being of Older Women Who Become Divorced or Separated in Mid and Later Life

No. 367: Alternative Pasts, Possible Futures: A "What If" Study of the Effects of Fertility on the Canadian Population and Labour Force

No. 368: Baby-Boom Aging and Average Living Standards

No. 369: The Impact of Reference Pricing of Cardiovascular Drugs on Health Care Costs and Health Outcomes: Evidence from British Columbia - Volume I: Summary

No. 370: The Impact of Reference Pricing of Cardiovascular Drugs on Health Care Costs and Health Outcomes: Evidence from British Columbia - Volume II: Technical Report

No. 371: The Impact of Reference Pricing of Cardiovascular Drugs on Health Care Costs and Health Outcomes: Evidence from British Columbia - Volume III: ACE and CCB Literature Review
K.M. Kobayashi

A. Martin-Matthews

C.J. Rosenthal

S. Matthews

A. Martin-Matthews K.M. Kobayashi C.J. Rosenthal S.H. Matthews

J.B. Burbidge L. Magee A.L. Robb

B.G. Spencer

S. Davies

M. Denton

F.T. Denton

C.H. Feaver

B.G. Spencer

W. Scarth

M. Souare

P.V. Grootendorst L.R. Dolovich A.M. Holbrooke

A.R. Levy B.J. O'Brien

P.V. Grootendorst

L.R. Dolovich

A.M. Holbrooke

A.R. Levy

B.J. O'Brien

L.R. Dolovich A.M. Holbrook M. Woodruff 
No. 372: Do Drug Plans Matter? Effects of Drug Plan Eligibility on

P. Grootendorst Drug Use Among the Elderly, Social Assistance Recipients M. Levine and the General Population

No. 373: Student Enrolment and Faculty Recruitment in Ontario: The Double Cohort, the Baby Boom Echo, and the Aging of University Faculty

No. 374: Aggregation Effects on Price and Expenditure Elasticities

F.T. Denton in a Quadratic Almost Ideal Demand System

B.G. Spencer

D.C. Mountain 